\title{
CUIDADO AOS HOMENS NO ENVELHECIMENTO: A FORMAÇÃO DOS PROFISSIONAIS DE SAÚDE
}

\author{
Men Care in the Aging Process: health professionals'formation
}

Artigo Original

\section{RESUMO}

Objetivo: Objetivou-se analisar a capacitação dos profissionais para realizar o cuidado no envelhecimento na perspectiva dos homens acima dos 50 anos. Métodos: Utilizou-se pesquisa qualitativa, em um município do interior do Estado de São Paulo. Coletou-se os dados em duas unidades da Estratégia Saúde da Família da área urbana e uma da região rural. Aplicou na coleta dos dados entrevista semi-estruturada com 24 homens com mais de 50 anos de idade, e a análise dos dados foi realizada pelo método de Análise de Conteúdo, modalidade temática. Resultados: Os homens compreendem o preparo dos profissionais pela maneira que são atendidos. Dessa forma, percebem que os profissionais estão capacitados para o cuidado ao terem estudo, mas o cuidado ainda é realizado de forma prescritiva sem identificar as necessidades e construir autonomia do sujeito. Mas também não tem capacitação para o cuidado nas suas necessidades no envelhecimento apontam que os profissionais não têm apoio da gestão dos serviços de saúde para operacionalizar as ações. Porém, outros acham que não estão preparados, justificando que depende de cada profissional ou que estes nem tem tempo para atendê-los. Conclusão: Identificamos que os currículos precisam de mudanças na abordagem dos conteúdos sobre o envelhecimento, bem como os profissionais necessitam de capacitação após sua formação para que haja melhora na reorganização e realização do cuidado, que os profissionais consigam abordar as necessidades de saúde na perspectiva da clínica ampliada.

Descritores: Envelhecimento; Saúde do Homem; Estratégia Saúde da Família.

\section{ABSTRACT}

Objective: The purpose of this study was to analyze qualification of professionals to perform care in the aging process from over 50-year-old men perspective. Methods: Qualitative research was used in a city in the countryside of São Paulo State. Data were collected at two Family Health Strategy units, one in the urban area and one in the rural region. Semistructured interviews with 24 men over 50 years of age were performed for data collection, and data analysis was performed using the Content Analysis method, thematic model. Results: Men understand professional preparation by the way they are treated. Thus, they realize professionals are qualified for care when they have a study, but care is still performed in a prescriptive way without identifying the needs and constructing subject autonomy. They also claim that professionals do not have any capacity for care during the aging process They point out that professionals do not have support from the health service management to carry the actions out. However, others feel that they are not prepared, justifying that it depends on each professional or that they do not have time to treat them. Conclusion: We identified that curricula need changing concerning the approach to aging content, as well as professionals need training and post-training so that there can be improvement in the reorganization and implementation of care, and professionals can address health needs under the perspective of expanded clinic.

Descriptors: Aging; Men's Health; Family Health Strategy.

\author{
Stéphanie Marques de \\ Camargo $^{(1)}$ \\ Mara Quaglio Chirelli ${ }^{(1)}$
}

1) Faculdade de Medicina de Marília FAMEMA - Marília (SP) - Brasil

Este artigo seguiu as normas e formatação estabelecidas pelo $5^{\circ} \mathrm{CIAIQ}$ - Congresso Ibero-Americano em Investigação Qualitativa. 


\section{INTRODUÇÃO}

Segundo o Instituto Brasileiro de Geografia e Estatística (IBGE) $^{(1)}$, entre o ano de 1950 e 2000, a população brasileira teve um aumento significativo de 51,9 milhões de pessoas para 190,7 milhões. E a previsão é de que no ano de 2000 até 2050 ocorrerá um aumento aproximado da população de 90 milhões, sendo que no ano de 2050, 48,9 milhões serão aqueles com 65 anos. Tendo assim, mudança com relação a expectativa de vida, dos 43,3 anos para $70,4 \operatorname{anos}^{(2)}$. O aumento no número populacional e no envelhecimento desses, ocorre de acordo com os determinantes sociais, econômicos, estilos de vida e culturais de cada sociedade, que modifica-se ao $\operatorname{logo}$ do tempo ${ }^{(3)}$. Além da evolução na ciência, tecnologias e na saúde.

Este estudo foi realizado na região do Departamento Regional da Saúde (DRS) IX Marília, tendo esta o segundo maior índice de envelhecimento do Estado de São Paulo, com 49,81 em 2010, sendo o índice do Estado de São Paulo no mesmo ano de $36,50^{(4)}$, sendo necessário vários estudos acerca desta área. No ano de 2010 , a população era de aproximadamente $29.594(13,7 \%)$ idosos ${ }^{(4)}$.

Há de se chamar a atenção para o crescente aumento no número da população idosa, e, assim, a necessidade de um investimento em políticas públicas de saúde, educação, bem estar social, dentre outras e a compreensão dos profissionais da área da saúde sobre o processo de envelhecimento saudável, ativo e seus determinantes. Dessa forma, tendo uma compreensão adequada sobre os determinantes consigamos promover a saúde e prevenir diversas situações de risco e sofrimentos. Mas, há também a necessidade de se investir na formação de profissionais de saúde para que estejam e se sintam preparados para construir junto aos usuários as informações adequadas, para que toda a população, não apenas os idosos, tenham um envelhecimento saudável.

Nesse contexto do envelhecimento, a situação de saúde dos homens chama atenção, considerando o alto índice de morbimortalidade relacionado à população masculina, os coeficientes de mortalidade dessa população são significativamente maiores comparados aos coeficientes de mortalidade femininos ${ }^{(5)}$. Segundo o $\operatorname{IBGE}^{(4)}$, no ano de 2010 a população feminina era, aproximadamente, de 97 milhões e a masculina de 93 milhões.

Outra questão referente aos homens diz respeito ao por que enfrentar e resolver o acesso aos serviços de saúde e as suas necessidades.

Estudo realizado nos serviços de atenção primária no México, tendo como foco compreender como diminuir risco de doenças cardiovascular em homens e seus familiares, identificou dificuldades na participação dos homens, porque alguns não procuram atendimento e não mantém sua saúde devido à falta de tempo, sendo esta uma justificativa listada por muitos participantes. Além disso, mesmo sabendo que são portadores de doenças crônicas, eles não procuram atendimento, por questão de orgulho, outros acreditam que homens e mulheres apresentam participações diferentes na sociedade, sendo assim, aqueles que procuram atendimento e participam de grupos de educação para a saúde são aqueles que realmente não estão bem na sua condição de $\operatorname{vida}^{(6)}$.

Segundo Silva et al.(7), as necessidades de saúde dos homens e o reconhecimento dela, sofrem influencia da sociedade, ou seja, da masculinidade. Os homens entrevistados informaram que necessidade significa entretenimento, lazer e qualidade de vida. Além disso, eles acreditam não serem frágeis e que outras pessoas precisam mais de atendimento e cuidado à saúde do que eles, assim, não necessitam de cuidados. Além disso, foi identificado sentimento de humilhação, pois os homens demonstraram temer que os vizinhos descubram que eles estão procurando atendimento de saúde.

Neste contexto, em 27 de agosto de 2009, de acordo com a Portaria MS/GM No 1.944 foi instituído, no Sistema Único de Saúde (SUS), a Política Nacional de Atenção Integral à Saúde do Homem (PNAISH) ${ }^{(5)}$.Com base nessa política as unidades de Estratégia de Saúde da Família (ESF), deveriam criar planejamentos e ações de promoção, prevenção e recuperação a saúde do homem. Permitindo assim, que os profissionais estejam preparados para atender as necessidades dos homens e para que eles se sintam bem acolhidos.

É necessário também que os profissionais de saúde tenham mais sensibilidade em relação às demandas trazidas pelos homens e criem ações para serem abordadas com a comunidade $^{(8)}$. Mas, para que isso aconteça, há a necessidade de capacitar os profissionais ${ }^{(5)}$.

Sendo assim, segundo a visão de profissionais enfermeiros a infraestrutura, a organização e a sistematização do atendimento não estão adequados e nem preparados para atender a população masculina. Além de que, a maioria dos entrevistados informou não conhecer a PNAISH e que outros profissionais e a população também desconhecem ${ }^{(9)}$.

Segundo Aguiar et al. ${ }^{(10)}$, puderam concluir após um estudo de revisão bibliográfica, que os profissionais enfermeiros necessitam conhecer, aprofundar e serem capacitados com o conteúdo da PNAISH. Pois, sem o preparo há a dificuldade em realizar o cuidado e de compreender as reais necessidades dos homens. É necessário que eles se sintam bem acolhidos, permitindo assim a quebra de barreira para a procura pelo atendimento de saúde, permitindo assim a procura pelo atendimento de prevenção. Mas para que isso aconteça, é importante ocorrer a organização por parte da gestão, permitindo um acolhimento coerente e que abranja os homens em suas necessidades. 
Assim, a educação em saúde é uma ferramenta importante, que permite a aproximação e conhecimento da população. No entanto, ainda há dificuldades para implementá-la nos serviços, não só devido a questão de infraestrutura, de materiais, de compreensões divergentes entre os profissionais, mas há também a gestão do trabalho que dificulta que seja inserida a educação na agenda dos profissionais. Assim, perde-se uma ferramenta que colaboraria muito para a promoção na saúde, dentre outros $\operatorname{aspectos}^{(11)}$.

Para se realizar um bom atendimento ao homem, o profissional deve ter conhecimento sobre o seu contexto de vida $^{(12)}$. Ao mesmo tempo que não adianta ter uma técnica específica ou estratégia para atender aos homens, pois cada um tem sua individualidade. Por isso, é necessário que haja investimento na área da saúde do homem e na comunidade. Sendo permitido que os profissionais estejam preparado a atender as variáveis demandas e melhorar a qualidade de vida e do atendimento.

Considerando estas necessidades, a Saúde do Homem deve ser trabalhada não só em capacitações em serviço dos profissionais, mas estar incluída durante a formação na graduação ou pós-graduação. O cuidado com o envelhecer, é a base para superar as atuais dificuldades enfrentadas. Em pesquisa realizada em ESFs com enfermeiros, a minoria apresentara experiência exclusiva em ESF e nenhum destes apresentara capacitação com relação ao cuidado na saúde do homem. De todas as unidades apenas uma realizava reuniões voltadas para a discussão do cuidado aos homens e todas as enfermeiras demonstram dificuldade de compreender e de realizar o acolhimento, ainda mais devido a pouca procura dos homens pela ESF, dificultando a compreensão das principais necessidades de saúde ${ }^{(13)}$.

Os programas de educação para o envelhecimento devem ser criados junto com a família, empresas, escolas, faculdades e devem ter início de preferência na infância. Além de realizar educação em saúde com a população que está em processo de envelhecimento, dando ênfase para os homens que ainda apresentam dificuldades no entendimento sobre o envelhecer e no autocuidado ${ }^{(14)}$.

Baseando-se nestes argumentos, consideramos como pressupostos: que os serviços de saúde têm apresentado dificuldades para organizar o processo de trabalho de forma a acolher as necessidades de saúde dos homens no seu processo de envelhecimento e que muitas vezes essas dificuldades são decorrentes da formação e capacitação deficiente dos profissionais de saúde que não instrumentalizam esses para captarem as necessidades e realizarem o cuidado ao homem; na visão dos homens eles procuram os serviços de saúde somente quando é muito necessário e não há outra alternativa, porém, nem sempre suas necessidades no processo de envelhecimento são percebidas e/ou atendidas.

Neste sentido, ao considerarmos a dificuldade que os homens apresentam em procurar os serviços de saúde para a prevenção de doenças e a promoção e recuperação da sua saúde, pergunta-se: como os homens percebem a capacidade dos profissionais para atendê-los no seu processo de envelhecimento?

Portanto, consideramos como objetivo desta pesquisa analisar a formação dos profissionais para o cuidado no processo de envelhecimento na visão dos homens acima dos 50 anos.

\section{MÉTODOS}

Realizada investigação por meio de pesquisa qualitativa, a qual incorpora os significados, as intencionalidades, os sentidos, os valores e atitudes a partir da realidade social ${ }^{(15)}$.

Trabalhamos com uma amostra de conveniência/ intencionalidade, e ao ser uma pesquisa exploratória, nos permite selecionar aleatoriamente um pequeno número de ESF, de participantes e gerar hipóteses ${ }^{(16)}$. Os dados foram coletados com usuários homens com idade superior a 50 anos, considerando a restrição do tempo de pesquisa.

A abordagem foi em um município do interior do Estado de São Paulo, Brasil, sendo selecionadas duas ESF da área urbana (região leste e sul) e uma da região rural, considerando o maior índice populacional dos homens acima de 50 anos.

Selecionou-se dois participantes em cada um dos intervalos das faixas etárias de 50 a 59 anos, 60 a 69 anos, 70 a 79 anos e 80 e mais, por Unidade de Saúde da Família (USF) para serem entrevistados, totalizando 24 participantes.

Utilizamos como critérios de inclusão: homens que utilizam ou não a USF; morem na área de abrangência da USF no período igual ou superior a um ano; tenham ou não agravos à saúde. E como critério de exclusão: homens com menos de 50 anos; morar a menos de um ano na área de abrangência da USF e terem dificuldades de comunicação e não conseguirem participar da pesquisa.

A pesquisa foi aprovada pelo Conselho Municipal de Avaliação em Pesquisa (COMAP) e pelo Comitê de Ética e Pesquisa da Faculdade de Medicina de Marília (FAMEMA), pelo Parecer $n^{\circ} 725.584$.

Respeitando os procedimentos previstos na Resolução 466/2012 do Conselho Nacional de Saúde (CNS), foi solicitado aos participantes que aceitaram integrar a pesquisa a assinatura do Termo de Consentimento Livre e Esclarecido (TCLE) ${ }^{(17)}$. Obtido o consentimento, o pesquisador solicitou também a autorização para que as 
atividades pudessem ter o registro em áudio por meio de gravador, com posterior transcrição, para fidedignidade do material coletado.

Inicialmente, realizamos um piloto para testar o instrumento de pesquisa com oito homens. Fizemos os ajustes necessários no instrumento e iniciamos a coleta dos dados.

$\mathrm{Na}$ coleta utilizou-se a entrevista semi estruturada tendo como disparador ${ }^{(18)}$ o questionamento: "O senhor acha que os profissionais estavam preparados/qualificados para atender as suas necessidades/problemas?".

O material foi coletado pela pesquisadora principal, no domicílio dos participantes, no período de abril a maio de 2015, o tempo de duração de cada entrevista foi de 6 a 45 minutos, em média 10 minutos. Durante a coleta de dados houve apenas uma recusa. Dos 24 participantes, todos residem na área de abrangência das USF e a mais de 10 anos no bairro. A maioria eram aposentados, isso se deve, talvez, pela coleta de dados ter sido durante o período do dia.

A análise do material coletado foi por meio do método da Análise de Conteúdo, modalidade temática, a qual desenvolve-se em três momentos ${ }^{(18)}$. No primeiro, denominado de Pré-análise, se realiza leitura flutuante, na qual resgatamos os objetivos e as hipóteses da investigação, e após várias e exaustivas leituras, constituímos o corpus $^{(18)}$. Neste momento foram identificadas também as categorias de análise e definidas a unidade de registro pelos fragmentos das falas.

Passou-se para o segundo momento, a exploração do material, inserimos os fragmentos das falas nas categorias, de forma que os materiais selecionados fossem as expressões mais representativas, organizando o material da pesquisa ${ }^{(18)}$. Nesse momento, fizemos também a identificação dos núcleos de sentido: falta de preparo dos profissionais com relação ao cuidado aos homens no envelhecimento e os profissionais tem formação para o cuidado aos homens no envelhecimento. Em seguida, realizamos o movimento de diálogo entre os núcleos de sentido para chegarmos ao tema: "a capacitação dos profissionais para o cuidado aos homens no envelhecimento".

No ultimo momento, realizou-se a análise e interpretação dos resultados, considerando as bases teóricas da educação e o modelo de atenção e gestão à saúde, para que com a ajuda desta fundamentação teórica fosse possível propor inferências ${ }^{(18,19)}$.

\section{RESULTADOS E DISCUSSÃO}

Dos homens entrevistados todos residem na área de abrangência das USF e há mais de 10 anos no bairro. Sendo que a maioria eram aposentados, isso se deve talvez pela coleta de dados ter sido durante o dia. Dos convidados a participarem, houve apenas uma recusa.

Quando realizado o questionamento aos homens sobre o preparo dos profissionais para atendê-los no seu processo de envelhecimento, responderam que havia preparo, assim, justificam o bom atendimento que receberam. Mas também identificam que nem sempre são atendidos na unidade de saúde, apontando um problema de gestão do sistema.

"[...] sim, eu acho que está! Ah porque, toda vez que eu fui lá eu fui bem atendido, Graças a Deus." (E24)

"[...] eles estão né?! só que às vezes não atende. Mas tão preparado sim."(E14)

Há aqueles que informaram que os profissionais estão preparados, tem conteúdo e noção de como pode ser realizada a prática, inclusive propondo medidas de promoção à saúde, mas não a executam, por não terem suporte dos gestores e podendo colocar em risco a sua inserção no serviço de saúde.

"Não sei [...] (risadas) eu acho que estão preparados sim. Por que são gente estudado, na medicina. [...] Em alto nivel." (E18)

“[...] eles têm preparo. Só que eles não estão sabendo ter suporte. Não adianta eu também criticar só o profissional. Às vezes ele tem vontade de fazer alguma coisa, mas ele não tem suporte, não tem apoio do poder público, [...] se ele insistir, ele vai perder o cargo dele também." (E23)

"Acho que preparado eles estão. É só que não está sendo desenvolvido o trabalho!?. Eles tinham que fazer um programa de acompanhamento, com caminhada, atividades fisica! [...]."(E4)

"Preparados eles estão. Mas é como eu disse, se ele vem falar com você uma coisa, e você obedece e faz o que ele te pedir, tudo bem, se não faz, vai achar que o médico [...] não sabe nada [...] Mas eles estão preparados." (E2);

Assim, os homens estão considerando que os profissionais estão capacitados para o cuidado ao terem estudo. Mas não só isso, destacam que há um problema de gestão. Frente à organização do trabalho, estes profissionais não têm apoio da gestão dos serviços de saúde para operacionalizar as ações. Destacam dentre as ações, práticas que superam o modelo biomédico, sendo essas o suporte para realizar o acompanhamento dos usuários com enfoque na promoção à saúde, como caminhadas e atividades físicas.

Outro destaque está na forma como o usuário percebe que está sendo realizado o cuidado, ou seja, ainda de forma prescritiva, sem identificar as necessidades e construir autonomia do sujeito. O (E2) destaca que o profissional se comunica com o usuário numa relação verticalizada, sem 
considerar os conhecimentos do outro no movimento da construção do plano de cuidados.

Devido ao aumento rápido no número de idosos no país, tornou-se imprescindível realizar mudanças nos serviços de saúde com foco na reorganização do processo de trabalho que atenda às necessidades dos idosos e no envelhecimento da população, ao mesmo tempo em que é extremamente necessário formar os novos profissionais já com o preparo para o atendimento a essa população. Porém, captar as necessidades a partir dos sujeitos do processo, tem se tornado essencial para que se tenha qualidade no cuidado por meio da produção da cogestão nesse cuidado, com responsabilização de ambos (profissional e homens) pelas ações produzidas. Busca-se também que essa forma de cuidado gere autonomia dos homens "no modo de andar a vida", ou seja, tendo a possibilidade dos homens também decidirem sobre as condutas a serem produzidas nos seus planos de cuidado.

Seguindo a lógica da ESF, existe a Clínica Ampliada que tem como princípio a junção e admissão de diferentes disciplinas, ou seja, há a integração com especialidades variadas, possibilitando um atendimento satisfatório e multiprofissional ${ }^{(20)}$. Além disso, é possível que haja a ruptura de práticas já existentes, permitindo assim, a integração e participação do usuário no seu cuidado ${ }^{(21)}$. Permitindo a realização da integralidade no cuidado.

Segundo Oliveira et al. ${ }^{(22)}$, é possível identificar as necessidades de saúde a partir da boa conversa e do atendimento interdisciplinar, com foco na clínica ampliada, podendo o atendimento ser conduzido adequadamente. A boa qualidade no atendimento pode resultar que o usuário compreenda suas necessidades de saúde, além de refletir sobre seus hábitos no dia a dia.

Mas para que isso ocorra é necessário organização, porém, na visão de profissionais de uma Unidade Básica de Saúde (UBS), há dificuldades internas, como a demora no agendamento de consultas, os turnos de funcionamento, falha ao recepcionar o cliente, insatisfação de funcionários e outros. Estas dificuldades ocorrem devido a grande demanda e a diminuição no número de funcionários, tendo destaque a classe médica ${ }^{(23)}$.

Sendo que, em outro estudo também pode ser identificado por profissionais da saúde e por usuários da ESF falhas ao longo de todo processo de atendimento ao usuário, sendo da entrada dele na unidade até a resolução total de suas necessidades. Chamando novamente a atenção na gestão do processo de trabalho e como isso reflete negativamente na relação com os usuários ${ }^{(24)}$.

Os entrevistados percebem que de uma forma geral os profissionais são capacitados, mas para o atendimento focado no envelhecimento não conseguem avaliar. Porém, outros acham que não estão preparados, justificando que depende de cada profissional ou que estes nem tem tempo para atendê-los. Destacam que o atendimento acontece somente uma vez por ano, e isto quando dá certo, quando não é possível, ficam sem o atendimento.

"Porque no conhecimento que eu tenho deles, eles são muito ótimos. Agora nessa parte ai ("envelhecimento"), não sei se eles estão preparados."(E3)

“[...] Acho que não! Está difícil. Porque [...] não dá tempo de atender, sei lá são poucos médicos, poucas pessoas para atender todo mundo. Atende uma vez por ano [...] quando dá certo, quando não dá, fica sem atender mesmo [...]." (E13)

"Ai depende muito de cada profissional. Porque tem uns que faz o curso e tem muitos que às vezes entra, muda de setor sem estar PREPARADO pra atender as pessoas."(E12)

A organização do processo de trabalho é destacada pelos homens frente à gestão de cada trabalhador se responsabilizar pela sua capacitação e isto interferir na qualidade do cuidado realizado no cotidiano. Destacam, também, a figura do gestor institucionalizado, na medida em que os homens apontam que há problemas na organização do cuidado frente ao número de profissionais médicos para atendê-los. Nesta visão ainda predomina o modelo biomédico, mas apontam a exigência da responsabilização por parte do gestor, para que se possa responder a um sistema que, em princípio, está sinalizado como um direito.

Desse modo, é necessário que o gestor tenha conhecimento sobre a política da Saúde do Homem, sendo possível realizar educação em saúde e podendo, assim, incentivar o cuidado nessa. Nesse sentido, coloca-se em pratica ações educativas de promoção e prevenção à saúde, mas para que todos os planejamentos e ações dêem certo, é importante que haja o conhecimento de sua população masculina, considerando as questões sociais, culturais, econômicas e princípios de cada um ${ }^{(25)}$.

Os homens também acreditam que os profissionais não estão capacitados, principalmente o médico, pois há a falta de conhecimento, preparo e dedicação na área deles, porque não respondem às necessidades nos serviços de saúde.

"Acho que não, [...] principalmente pelos profissionais médicos que passaram pelo posto, deixaram muito a desejar. Eu vejo que falta um pouco mais de conhecimento, dedicação profunda na área deles [...]." (E5)

Desse modo, segundo as Diretrizes Curriculares Nacionais (DCN) do Curso de Medicina, revisada em 2014, no Artigo $3^{\circ}$ as quais destacam que, o estudante de medicina terá aptidão para realizar promoção, prevenção, 
recuperação e reabilitação da saúde individual e coletiva, de forma ética, humanizada e crítica. Além de que, na Atenção a Saúde (Seção I) o discente deverá realizar a integralidade no cuidado, por meio de práticas e projetos terapêuticos, estimulando a autonomia e o autocuidado individual e da comunidade. O profissional terá conhecimento sobre envelhecimento (capítulo III), além de trabalhar com o cuidado a partir da promoção da saúde e entendimento fisiológicos do ser humano durante o nascimento, crescimento, envelhecimento e a morte, entre outros (art. 23 , item $\mathrm{VI})^{(26)}$.

As DCN do curso de medicina foram modificadas recentemente, sendo assim, tem-se a expectativa que os futuros profissionais médicos possam se formar com um melhor preparo para o atendimento ao envelhecimento. Nesse sentido, identificamos que a Saúde do Homem possa ser abordada no contexto da saúde do adulto e do idoso, podendo também ocorrer mudanças no cuidado ${ }^{(27)}$.

Segundo os profissionais de uma unidade de saúde, há a necessidade de estender o horário de atendimento, para que a unidade consiga resolver as necessidades de saúde, melhorar $\mathrm{o}$ atendimento, melhora na comunicação e que sejam realizadas visitas domiciliarias, proporcionando vinculo entre unidade de saúde e o usuário homem ${ }^{(28)}$. Mas, para que haja a satisfação no atendimento ao envelhecimento do homem, é necessário que o profissional esteja preparado.

Vários são os motivos que interferem em uma boa qualidade de atendimento aos homens, e alguns deles estão relacionados ao trabalho dos profissionais de saúde, como a inadequação da estrutura física e a falta de educação continuada. A política da saúde do homem e o foco em sua saúde são considerados temas recentes, ainda mais porque as instituições acadêmicas não abrangem essa temática em suas grades curriculares ${ }^{(25)}$. Chamando a atenção para $o$ atendimento no seu processo de envelhecimento que acontece em todo os momentos de sua vida.

Em muitos casos há a dificuldade pelos profissionais de saúde em realizarem a integralidade no cuidado. Segundo eles, isso se deve ao aumento na procura por atendimento, falta de tempo, queda no número de profissionais, além de serem cobrados constantemente em terem que atingir metas $^{(29)}$. Consequentemente, os profissionais deixam de lado a integralidade e o atendimento baseado na clínica ampliada, tendo como resultado a realização do cuidado a partir da clínica reduzida. Assim, os usuários saem se sentindo insatisfeitos com o atendimento.

Segundo estudo, os profissionais devem oferecer um bom atendimento aos idosos, sendo preciso antes de qualquer coisa, compreender sua realidade social, cultural, limitações, nível de aprendizado, entre outros; para que possam ser conhecidas as suas necessidades e que boas estratégias possam ser elaboradas ${ }^{(30)}$.
Pois se mudanças não forem realizadas, os homens continuarão recebendo atendimento nas unidades de saúde focado em aspectos biológicose somente em tratamentos de doenças crônicas e urgentes ${ }^{(31)}$.

Desse modo, se os profissionais ampliarem a forma de realizarem sua prática e conhecerem integralmente seus pacientes homens, será possível que ocorra a redução das barreiras que existem, permitindo, assim, a acessibilidade deles nas unidades de saúde e a criação de vínculo entre eles e a equipe ${ }^{(32)}$.

Os participantes da pesquisa questionam sobre a formação de clinico geral do profissional da Atenção Básica (AB) para o atendimento na Saúde do Homem; relatam que o profissional não tem conhecimento sobre a área que irão cuidar.

"Aqui nesse posto não. Porque [...] temos um ginecologista feminino, já falou pra mim que ele entende de mulher, de homem ele não entende, e eu não discordo dele. Ele estudou ginecologista feminino não masculino. No meu caso, que eu fui lá da próstata, ele falou, vai procurar um especialista.[...] E eu fui bem. Acho que devia ter um clínico geral, não sei, ele é clinico geral?." (E10)

Os usuários homens questionam que para cuidar deles, com problema específico dos homens (próstata), precisaria ser clínico geral. Destacamos que, no Brasil, o profissional médico tem formação inicial com base no perfil de médico generalista, estabelecido na DCN, assim, as ESFs contratam profissionais capacitados para realizar o primeiro atendimento na $\mathrm{AB}$ e que poderiam resolver as situações nesse serviço, e, quando necessário, encaminhase para especialidade médica e multiprofissional ${ }^{(27)}$. Porém, questionamos o quanto o profissional se compromete com a resolução dos problemas ou se foi formado para captar e cuidar das necessidades dos homens, ou mesmo se as instituições de ensino estão preparando estes profissionais para atuar no processo de envelhecimento das pessoas e, em especial dos homens.

Em estudo os homens afirmam a necessidade de que tenha mais profissionais médicos para atendê-los, diminuindo assim, a espera pelo atendimento. Quando questionados sobre obstáculos para procurarem o atendimento, informam a demora no mesmo, a vergonha de procurar o profissional, falta de tempo para ficarem aguardando e que a unidade não consegue resolver suas necessidades ${ }^{(28)}$.

Como identificado em outro estudo, os homens afirmam procurarem atendimento de saúde avançado devido à falta de tempo e por acreditarem que esse é melhor. Assim, eles associam o bom atendimento dos serviços avançados com o maior numero de profissionais disponíveis para atendê-los. Além de muitos não compreendem a proposta oferecida na $\mathrm{ESF}^{(33)}$. 
Neste sentido, é necessário que os profissionais das unidades de saúde se organizem, para compreender melhor as necessidades e demandas dos homens ${ }^{(27)}$. Além disso, há, também, investimento no processo de formação dos profissionais da equipe de saúde, em particular do médico, considerando que ainda estamos em processo de desconstrução do modelo biomédico e em busca de novas formas de organizar as práticas em saúde.

Em uma Universidade do Brasil foi observada a compreensão dos acadêmicos sobre o envelhecer, sendo identificado como algo normal e que possa ou não vir acompanhado de algum problema de saúde. O contato que eles tem com o tema é durante a realização das atividades práticas e durante os estudos ao longo dos anos na graduação. Mas, quando questionados sobre a opinião pessoal sobre o envelhecimento, informam que a destruição do corpo humano é devido a fatores orgânicos e externos, ao mesmo tempo é um processo que os deixa mais perto do momento da morte, há o medo da independência, limitações. Citam ainda que não estão preparados para lidar com o velho, ainda mais que o idoso perde seu valor frente à sociedade. Mas há os que veem o lado positivo, talvez pelo conhecimento alcançado ${ }^{(34)}$.

Em contrapartida, em estudo realizado em Portugal, com escolas com o curso de enfermagem, foi identificado que há assistência ao idoso, sendo na área hospitalar, no cuidado ao adulto, cuidado ao idoso, cuidado a família, há aproximação com definições do envelhecimento, atenção comunitária e legislações ${ }^{(35)}$.

Este mesmo autor ainda destaca que a formação na área do cuidado ao idoso requer que os futuros enfermeiros desenvolvam os cuidados a esta pessoa de forma adequada. Considerando-se que os estudantes já cuidam de pessoas idosas em quase todas as aulas práticas, vivências clínicas e estágios, muitas vezes em situação de doença, tornandose necessário uma matéria/disciplina que direcione mais o estudante à promoção da saúde do idoso e a manutenção do envelhecimento ativo ${ }^{(35)}$.

Segundo estudo realizado por Carvalho e Hennington ${ }^{(36)}$, algumas das universidades Brasileiras abordam o tema sobre envelhecimento, mas as universidades internacionais abordam mais, tanto na pratica como em sala de aula. Os autores chamam a atenção para que haja a melhora no desenvolvimento das disciplinas e que não fique focado apenas em conhecimento a ser adquirido nas faculdades. Essa temática deve ser trabalhada antes do período de faculdade e depois com educação continuada e permanente.

Frente à percepção do usuário, identificamos a necessidade de que os discentes tenham formação na graduação voltada para o cuidado ao homem no seu processo de envelhecimento, num currículo no qual possa articular a formação ao mundo do trabalho. Neste sentido, os estudantes poderiam construir o conhecimento a partir da diversidade das situações da realidade, por meio do confronto experiencial com esta. A intencionalidade estaria voltada para a melhoria da compreensão do processo de envelhecimento, do processo de cuidar do homem no envelhecimento, como também da família e da comunidade.

Mas quando analisada as DCN do Curso de Graduação em Enfermagem, o enfermeiro deve ter ênfase no SUS, devendo abordar as necessidades sociais de saúde por meio da integralidade, ética e humanização no cuidado ${ }^{(37)}$.

Durante a formação, segundo as DCN, o enfermeiro deve participar e organizar assistência integral à criança, adolescente, mulher, adulto e o idoso, focando na saúde desses. Nos conteúdos essenciais para a graduação na área de ciências da enfermagem deve ser construído o conhecimento sobre os fundamentos de enfermagem e assistência de enfermagem ao nível individual e coletivo, trabalhando conteúdos da atenção às crianças, ao adolescente, adulto, à mulher e ao idoso ${ }^{(38)}$.

A Saúde do homem nos currículos acadêmicos, pode estar inserida dentro da saúde do adulto, diluída nestes conteúdos, ou simplesmente não existir. Sendo assim, identifica-se que ambos os conteúdos não são destacados, assim, há de se chamar a atenção para a necessidade de mudanças curriculares e para que a abordagem do envelhecimento possa ser inserida ao longo do currículo e não somente no momento da saúde do idoso ${ }^{(27)}$.

Atualmente, considera-se pelos documentos oficiais, como o estatuto do idoso, que uma pessoa é idosa quando ela apresenta idade igual ou superior a 60 anos, independente de seu estado de saúde, tanto mental, físico e social ${ }^{(39)}$. Mas é importante compreender que o envelhecimento não é apenas uma questão cronológica, mas os resultados de como as pessoas agem no seu dia a dia, sendo uma articulação das experiências vividas socialmente, das condições culturais, políticas, econômicas e geográficas, as quais influenciam no estado mental, físico, cronológico e social, bem como nas representações sociais da velhice e também dos idosos ${ }^{(40)}$.

Considerando a nossa transição epidemiológica e o aumento da população de idosos, não podemos postergar mais a inserção destes conteúdos na organização curricular, necessitando de estratégias para a formação de docentes, permitindo que haja a integração com serviços de saúde para que estes possam se organizar junto com a academia para que as práticas profissionais também estejam organizadas de acordo com as necessidades da saúde do homem e na perspectiva do envelhecimento.

\section{CONSIDERAÇÕES FINAIS}

Segundo os entrevistados alguns profissionais de saúde estão preparados em atender o homem em seu processo 
de envelhecimento e outros acreditam que não estão. Essa visão depende do modo como foram recebidos, acolhidos e atendidos nas unidades de saúde, além disso, depende também da organização dessas, do processo de trabalho e das atividades oferecidas.

Por isso, há de se chamar a atenção para que os profissionais de saúde conheçam melhor os homens a partir do seu território e suas necessidades e demandas, ou seja, conhecendo suas necessidades socioculturais, biológicas, econômicos, psicológicas e espirituais.

A Política de Saúde do Homem é considerada nova no Brasil, esse pode ser um dos determinantes para a não implementação desse conteúdo nos currículos das universidades. Além disso, talvez a saúde do homem possa estar sendo abordada junto ao conteúdo da saúde do adulto. Assim, é necessária que seja realizada investigação específica nesta área para que possamos ter clareza sobre o processo de formação dos profissionais da saúde.

Nota-se a necessidade de que ocorram investimentos, mudanças e melhorias curriculares, educação permanente, educação continuada, capacitações, e, dessa forma, construir ações voltadas para os homens no seu processo de envelhecimento e para a comunidade.

Nos serviços de saúde a gestão necessita desenvolver ações estratégicas tanto para capacitar os profissionais para o cuidado, como para organizar as ações nas unidades de saúde e se comprometer com as práticas na perspectiva da clínica ampliada, para que se possa ter um cuidado ao homem no envelhecimento enquanto sujeito, podendo estabelecer relações verticais no cuidado, nas quais o homem se sinta acolhido pelos profissionais em suas necessidades.

\section{REFERÊNCIAS}

1. IBGE. Estatítica da população [Internet]. Rio de Janeiro (RJ);2010. [citdo 26 out 2016]. Disponível em: http://www.ibge.gov.br/home/estatistica/populacao/ censo2010/

2. IBGE. Tendências demográficas no período de 1950/2000 [Internet]. Rio de Janeiro (RJ); 2001. [citado 26 dez 2016]. Disponível em: http://www.ibge.gov.br/ home/estatistica/populacao/censo2000/tendencias demograficas/comentarios.pdf

3. Geib LTC. Determinantes sociais da saúde do idoso. Ciênc. Saúde Coletiva. 2012;17(1):123-33.

4. IBGE. Características da população [Internet]. Rio de Janeiro (RJ); 2010. [citado 26 out 2016]. Disponível em: http://7a12.ibge.gov.br/vamos-conhecer-o-brasil/ nosso-povo/caracteristicas-da-populacao

5. Brasil. Ministério da Saúde. Gabinete do Ministério. Portaria n. 1944 de 27 de agosto de 2009. Institui no âmbito do Sistema Único de Saúde (SUS), a Política Nacional de Atenção Integral à Saúde do Homem. Diário Oficial da União, Brasília (DF); 28 ago 2009; Seção 1: 61.

6. Fort MP, Castro M, Penã L, Hernández SHL, Camacho GA, Ramírez-Zea M, Martínez H. Opportunities for involving men and families in chronic disease management: a qualitative study from Chiapas, Mexico. BMC publichealth (Online). 2015;5:1019.

7. Silva LA, Corrêa ACP, Fraga JCAXO, Rodrigues TC, Divino EA. Percepções de homens trabalhadores sobre suas necessidades de saúde em um serviço universitário de saúde. Cienc Cuid Saude. 2016;15(1):133-40.

8. Figueiredo W. Assistência à saúde dos homens: um desafio para os serviços de atenção primária. Ciênc. Saúde Coletiva. 2005;10(1):105-9.

9. Silva PAS, Furtado MS, Guilhon AB, Souza NVDO, David HMSL. Saúde do homem na visão do enfermeiro. Esc Anna Nery Rev Enferm. 2012;16(3):561-8.

10. Aguiar RS, Santana DC, Santana PC. A percepção do enfermeiro da estratégia saúde da família sobre a saúde do homem. Rev. Enferm. Cent.-Oeste Min. 2015;5(3):1844-54.

11. Silva JRA, Lemos EC, Hardman CM, Santos SJ, Antunes MBC. Educação em saúde na estratégia de saúde da família: percepção dos profissionais. Rev Bras Promoç Saúde. (Impr.). 2015;28(1): 75-81.

12. Malcher G. Engaging men in health care. Aust. Fam. Physician. 2009;38(3):92-5.

13. Santana EM, Lima EMM, Bulhões JLF, Monteiro EMLM, Aquino JM. A atenção à saúde do homem: ações e perspectivas dos enfermeiros. REME Rev Min Enferm. 2011;15(3):324-32.

14. Queiroz ZPV, Ruiz CR, Ferreira VM. Reflexões sobre o envelhecimento humano e o futuro: questões de ética, comunicaçãoe educação. Rev Kairós.2009;12(1):21-37.

15. Minayo MCS. O envelhecimento da população brasileira e os desafios para o setor saúde [Editorial]. Cad Saúde Pública. 2012;28(2):208-9.

16. Marotti J, Galhardo APM, Furuyama RJ, Campos TN, Laganá DC. Amostragem em pesquisa clínica: tamanho da amostra. Rev. Odontol. Univ. Cid. São Paulo. 2008;20(2):186-94.

17. Brasil. Ministério da Saúde. Conselho Nacional de Saúde. Resolução n. 466, de 12 de dezembro de 2012. Aprova as diretrizes e normas regulamentadoras de pesquisas envolvendo seres humanos. Diário Oficial da União (DF); 13 jun 2013; Seção 1:59. 
18. Minayo MCS. O desafio do conhecimento: pesquisa qualitativa em saúde. $13^{\mathrm{a}}$ ed. São Paulo (SP): Hucitec; 2013.

19. Bardin L. Análise de conteúdo. São Paulo (SP): Edições 70; 2012.

20. Brasil. Ministério da Saúde. Clínica Ampliada e Compartilhada [Internet]. Brasília (DF); 2009. [citado 23 out 2016]. Disponível em: http://bvsms.saude.gov. br/bvs/publicacoes/clinica_ampliada_compartilhada. pdf

21. Brito DAS, Oliveira ISC, Resende JWR, Freitas LM. A transdisciplinaridade na construção da prática psicológica e no campo da clínica. 2015;5(14):75-87.

22. Oliveira BN, Alves EAS, Araújo CA, Santos ALB, Souza Neto LCV, Maia Neto JP. Saúde do homem na atenção primária à saúde: reflexões acerca da multiplicidade de olhares na avaliação corporal. Rev. Baiana Saúde Pública. 2014;38(3):751-9.

23. Dilélio AS, Tomasi E, Thumé E, Silveira DS, Siqueira FCV, Piccini RX, Silva SM, Nunes BP, Facchini LA. Padrões de utilização de atendimento médico ambulatorial no Brasil entre usuários do Sistema Único de Saúde, da saúde suplementar e de serviços privados. Cad. Saúde Pública. 2014;30(12):2594-606.

24. Viegas, APB, Carmo RF, Luz ZMP. Fatores que influenciam o acesso aos serviços de saúde na visão de profissionais e usuários de uma unidade básica de referência. Saúde Soc. 2015;24(1):100-12.

25. Rocha EM, Medeiros ADL, Rodrigues KSLF, Cruz JPM, Siqueira MFC, Farias EFN, Lemes AG. A política nacional de saúde do homem e os desafios de sua implementação na atenção primária à saude. Interdisciplinar: Revista Eletrônica da UNIVAR. 2016;15(1):43-48.

26. Brasil. Ministério da Educação. Conselho Nacional de Educação, Câmera de Educação Superior. Resolução CNE/CES No 3, de 20 de junho de 2014. Institui Diretrizes Curriculares Nacionais do Curso de Graduação em Medicina e dá outras providências. Diário Oficial da União, Brasília (DF); 23 de jun de 2014. Seção 1: 8-11.

27. Camargo SM, Chirelli MQ.A formação dos profissionais para o cuidado aos homens no envelhecimento. Investigação qualitativa (CIAIQ2016). 2016; 2: 84756. Diponível em: http://proceedings.ciaiq.org/index. php/ciaiq2016/article/view/830/816.

28. Cavalcanti JRD, Ferreira JA, Henriques AHB, Morais GSN, Trigueiro JVS, Torquato IMB. Assistência integral a saúde do homem: necessidades, obstáculos e estratégias de enfrentamento. Esc Anna Nery Rev Enferm. 2014;18(4):628-34.

29. Coutinho AT, Popim RC, Carregã K, Spiri WC. Integralidade do cuidado com o idoso na estratégia de saúde da família: visão da equipe. Esc Anna Nery Rev Enferm. 2013;17(4):628-37.

30. Mendes CKTT, Moreira MASP, Bezerra VP, Sarmento AMM, Silva LA, Sá CMCP. Atendimento para idosos na atenção básica de saúde: representações sociais. RevPesquiCuid Fundam (Online). 2013;5(1):3443-52. Disponível em: http://www.seer.unirio.br/index.php/ cuidadofundamental/article/view/2873/pdf_704

31. Moreira MA, Carvalho $\mathrm{CN}$. Atenção integral à saúde do homem: estratégias utilizadas por enfermeiras(os) nas Unidades de Saúde da Família do interior da Bahia. Saúde Transform. soc. 2016;7(3):121-32.

32. Storino LP, Souza KV, Silva KL. Necessidades da saúde de homens na atenção básica. Esc Anna Nery Rev Enferm. 2013;17(4):638-45.

33. Barreto MS, Arruda GO, Marcon SS. Como os homens adultos utilizam e avaliam os serviços de saúde. Rev. Eletrônica Enferm. 2015; 17(3):1-8.

34. Oliveira ALB, Dourado MB, Menezes TMO. A percepção dos graduandos de enfermagem sobre envelhecimento. Rev. Enferm. UERJ. 2014;22(5):6805.

35. Santo SSSC, Lopes MJ, Gemito ML, Casas-Novas MV, Pinheiro FT. Ensino do cuidado ao idoso na formação do enfermeiro: situação em Portugal. Rev RENE. 2013;14(4):801-10.

36. Carvalho CRA, Hennington EA. A abordagem do envelhecimento na formação universitária dos profissionais de saúde: uma revisão integrativa. Rev. Bras. Geriatr. Gerontol. 2015;18(2):417-31.

37. Freitas MC, Mendes MMR. O ensino sobre o processo de envelhecimento e velhice nos cursos de graduação em enfermagem. Rev. Bras. Enferm. 2003;56(5):5027.

38. Brasil. Ministério da Saúde. Conselho Nacional de Educação, Câmara de Educação Superior. Resolução $\mathrm{CNE} / \mathrm{CES} \mathrm{N} \mathrm{N}^{\circ}$ 3, de 7 de novembro de 2001. Institui Diretrizes Curriculares Nacionais do Curso de Graduação em Enfermagem. Diário Oficial da União, Brasília (DF); 9 de nov 2001. Seção 1: 37.

39. Brasil. Presidência da Republica. Lei $n^{\circ} 10.741$, de $1^{\circ}$ de outubro de 2003. Dispõe sobre o Estatuto do Idoso 
e dá outras providências [Internet]. Diário Oficial da União, Brasília (DF); 3 out 2003. [citado 26 out 2016]. Disponível em: http://www.planalto.gov.br/ccivil_03/ leis/2003/L10.741.htm

40. Schneider RH, Irigaray TQ. O envelhecimento na atualidade: aspectos cronológicos, biológicos, psicológicos e sociais. Estudo Psicol (Campinas). 2008;25(4):585-93.
Endereço para correspondência:

Stéphanie Marques de Camargo

Faculdade de Medicina de Marília

R. Monte Carmelo, 800

Bairro: Fragata

CEP: 17519-030 - Marília - SP - Brasil

E-mail: stephanie-camargo@hotmail.com 